\title{
Reduksi Gaya Drag Silinder Sirkular dengan Penambahan Square Disturbance Body Melalui Simulasi Numerik 2D Unsteady-RANS pada Reynolds Number 34800
}

\author{
Rina $^{1}$, Ruzita Sumiati ${ }^{2}$ Adriansyah ${ }^{2}$ \\ ${ }^{1}$ Program Studi Teknik Mesin, Universitas Dharma Andalas, Jl. Sawahan No. 103A, Padang, Indonesia \\ ${ }^{2}$ Jurusan Teknik Mesin, Politeknik Negeri Padang, Kampus Limau Manis, Padang, Indonesia
}

INFORMASI ARTIKEL

\section{Sejarah Artikel:}

Diterima Redaksi: 06 Agustus 2018

Revisi Akhir: 24 September 2018

Diterbitkan Online: 29 Oktober 2018

\section{KATA KUNCI}

circular cylinder

square disturbance body

drag pressure coefficient

drag force

turbulent flow

KORESPONDENSI

E-mail: rina.mesin@gmail.com

\begin{abstract}
A B S T R A C T
Circular cylinder has a strong adverse pressure gradient. When a fluid flows around the circular cylinder, it will produce aerodynamics force. One of them is the drag force which strong enough. Hence, control of flow need to reduce the drag force with placed a disturbance body on the upstream side. The purpose of this study is to compare and complement the experimental research of drag reduction that has been done before. The aerodynamics characteristics of the disturbance body and cylinder are modelled in two dimensions Unsteady-RANS by using fluent with turbulent flow. It is found that the mean drag and the lift fluctuation of the cylinder can be reduced by the upstream disturbance body with the $\mathrm{s} / \mathrm{D}=0.107$ (here $\mathrm{s}$ and $\mathrm{D}$ are side length of the disturbance body and the diameter of cylinder, respectively). The position of the disturbance body is varied at $(\alpha) 20^{\circ}, 30^{\circ}, 40^{\circ}, 50^{\circ}$ and $60^{\circ}$ with a gap distance $(\delta=0.4 \mathrm{~mm})$. Reynolds number based on cylinder diameter $\mathrm{ReD}=$ $3.48 \times 10^{4}$. Fluid interaction between circular cylinder with two disturbance body can increase boundary layer transition from laminer to turbulent to produce small drag. It is found that the characteristics of the flow significantly depend on the position of disturbance body. The optimum condition for the drag force reduction is at the angle $\alpha=30^{\circ}$ about $53 \%$.
\end{abstract}

\section{PENDAhULUAN}

Karakteristik aliran di sekitar bluff body bisa dianalisa melalui filosofi boundary layer. Diketahui bahwa boundary layer sangat berkontribusi dalam pengurangan gaya drag di sekitar body yang dilalui fluida karena adanya pengaruh tegangan geser. Tegangan geser pada permukaan body dipengaruhi oleh distribusi tekanan yang terjadi pada kontur body, dimana karakteristik distribusi tekanan ini dipengaruhi oleh geometri body.
Beberapa penelitian telah dilakukan untuk mengetahui fenomena yang terjadi pada aliran yang melintasi bluff body, baik itu untuk kepentingan akademik maupun industri. Pengurangan drag dilakukan dengan cara memanipulasi atau mengontrol medan aliran. Penelitian terkait ini sangat besar perannya dalam hal kemajuan teknologi, karena dengan berkurangnya gaya drag maka bahan bangunan akan dapat diselamatkan. Bentuk geometri body yang sering digunakan adalah berbentuk circular cylinder. Gerakan fluida yang melewati circular 
cylinder banyak kita lihat aplikasinya pada struktur bangunan-bangunan yang menggunakan bentukbentuk dasar bluff body seperti jembatan, cerobong asap, sistem perpipaan, cooling tower, tiang, struktur penyangga anjungan lepas pantai, dan lain sebagainya.

Kita ketahui bahwa, bentuk bluff body circular cylinder memiliki kelengkungan kontur permukaan dengan karakteristik Adverse Pressure Gradient (APG) yang kuat karena dominan dipengaruhi oleh pressure drag yang disebabkan oleh tekanan aliran pada permukaan body. Gradient tekanan yang terjadi pada permukaan body ini sangat besar sehingga mengakibatkan transisi lapis batas laminar menjadi turbulen akan lebih cepat terjadi.

Penelitian yang telah dilakukan dalam usaha pengurangan gaya drag dengan penambahan body pengganggu (upstream disturbance body) yang disusun secara tandem telah dilakukan oleh Tsutsui dan Igarashi [1], Lee, dkk [2], dan Zhang [3]. Mereka melakukan penelitian dengan menvariasikan rasio jarak longitudinal antara upstream disturbance body dengan silinder sirkular utama (L/D), rasio diameter upstream disturbance body dengan diameter silinder sirkular utama (d/D) dan Reynolds number. Boundary layer yang terseparasi dari kontur permukaan disturbance body akan membentuk free shear layer yang menghasilkan discrete vortices dan mengenai permukaan depan sirkular silinder utama. boundary layer pada silinder utama berinteraksi dengan Free shear layer. Hal ini menyebabkan transisi lapis batas laminer menjadi turbulen pada silinder utama akan lebih cepat terjadi sehingga separasi masif tertunda ke belakang, akibatnya gaya drag dapat direduksi.

Model konfigurasi bluff body yang disusun secara tandem juga digunakan oleh Daloglu [4] dalam penelitiannya. Dia menggunakan square cylinder yang ditempatkan pada sisi upstream dan circular silinder pada sisi downstrem. Variasi yang dilakukan adalah besarnya diameter sirkular silinder $(\mathrm{D}=\mathrm{d}, \mathrm{D}=2 \mathrm{~d}, \mathrm{D}=3 \mathrm{~d})$, dan rasio jarak longitudinal antara square cylinder pada sisi upstream dengan circular cylinder terhadap diameter circular cylinder (S/d). Hasil penelitiannya menjelaskan bahwa variasi jarak antar silinder memberikan pengaruh terhadap reduksi gaya drag, yaitu pada ratio jarak 1-1,5. Informasi lain yang dapat dilihat adalah square cylinder mempunyai nilai pressure drop lebih besar dari pada nilai circular cylinder.

Alam, dkk [5] dan Putra [6], menggunakan 2 buah body pengganggu masing-masing circular cylinder dan square cylinder, dengan variasi sudut pengganggu tertentu. Penelitian mereka menyebutkan bahwa penambahan body pengganggu pada sisi upstream silinder utama pada sudut tertentu memberikan pengaruh terhadap pengurangan gaya drag. Nilai optimum dalam pencapaian pengurangan gaya drag adalah pada sudut $\alpha=30^{\circ}$ Hal ini disebabkan pada sudut tersebut separasi masif tertunda sangat signifikan, ini terjadi karena adanya reattachment aliran pada silinder utama akibat dari penambahan disturbance body. Sedangkan pada sudut $\alpha=60^{\circ}$ tidak memberikan kontribusi dalam pengurangan gaya drag, karena aliran setelah melewati silinder pengganggu langsung terseparasi tanpa terdefleksi kembali ke silinder utama. Kemudian Weidman [7] dan Bell [8] meneliti pengaruh rasio dimensi bluff body dengan luasan saluran (blockage effect) terhadap kecepatan fluida dan koefisien hambatan. Kecepatan free stream akan meningkat karena adanya blockage effect. Dari hasil penelitian tersebut, mereka mengatakan bahwa semakin besar nilai blockage effect maka koefisien drag (Cd) akan semakin meningkat. Hal ini disebabkan karena dinding wind tunnel mengalami peningkatan dalam kecepatan free stream yang disebabkan oleh solid blockage yang juga berpengaruh terhadap pertumbuhan wake.

Freitas [9] merekomendasikan beberapa hal penting dalam melakukan simulasi numerik, yaitu turbulent modeling seperti RANS, URANS, LES, DES, boundary condition, initial condition, bentuk dan kerapatan meshing (grid independence) terutama di daerah dekat dinding (solid surface), sehingga didapatkan hasil yang sesuai dengan hasil eksperimen yang telah dilakukan sebelumnya. 
Dari beberapa penelitian tersebut, pembahasan tentang terjadinya peningkatan intensitas turbulensi dari free shear layer yang terseparasi dari body penggangggu yang kemudian melekat kembali (attach) pada kontur silinder utama di dalam medan free stream belum dibahas lebih rinci, sehingga perlu dibahas lebih lanjut dengan menampilkan kontur visualisasi aliran pada simulasi numeric menggunakan software FLUENT 6.3.26.

\section{METODOLOGI}

Karakteristik aerodynamics dari silinder dan pengganggu dimodelkan secara Numerik 2D Unsteady-RANS menggunakan Turbulen Model Shear-Stress-Transport (SST) $k-\omega$ pada saluran sempit. Geometri body yang disimulasikan adalah circular cylinder sebagai main bluff body dengan diameter $37.5 \mathrm{~mm}, 2$ buah square cylinder sebagai body pengganggu dengan panjang sisi $4 \mathrm{~mm}$ ( $\mathrm{s} / \mathrm{D}=0.107)$ yang ditempatkan di sisi depan main bluff body. Sudut body pengganggu yang digunakan adalah $\alpha=20^{\circ}, 30^{\circ}, 40^{\circ}, 50^{\circ}$ dan $60^{\circ}$ dengan jarak gap $\delta=0,4 \mathrm{~mm}$. Reynolds Number digunakan berdasarkan diameter silinder, yaitu $3.48 \times 10^{4}$.

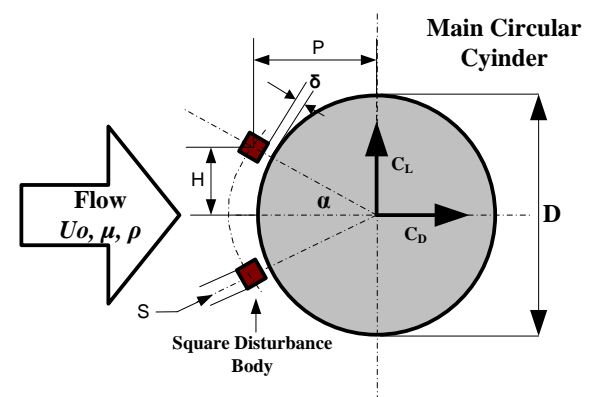

Gambar 1. Skema geometri silinder sirkular dengan square disturbance body

Hasil post-processing dari simulasi numerik dengan CFD solver FLUENT 6.3.26 menghasilkan data kuantitatif maupun kualitatif (visualisasi aliran). Koefisien tekanan adalah data kuantitatif yang merupakan pembagian dari tekanan statis dibagi dengan tekanan dinamik seperti diuraikan pada persamaan berikut:

$\mathrm{Cp}=\left(\rho_{\mathrm{c}}-\rho_{\infty}\right) / 1 / 2 \mathrm{\rho}_{\infty}^{2}$ dimana $p_{c}$ adalah tekanan pada kontur silinder sirkular, $\mathrm{p}_{\infty}$ adalah tekanan statis pada freestream, dan $1 / 2 \rho \mathrm{U}_{\infty}^{2}$ adalah tekanan dinamik pada free-stream.

Koefisien pressure drag (Cdp) diperoleh dengan mengintegrasikan koefisien tekanan $(\mathrm{Cp})$ kontur permukaan silinder.

$\mathrm{Cdp}=\frac{1}{2} \int_{0}^{2 \pi} \mathrm{C}_{\mathrm{p}}(\theta) \cos (\theta) \mathrm{d} \theta$

Untuk mendapatkan harga koefisien drag pressure (Cdp) maupun koefisien drag total $\left(\mathrm{C}_{\mathrm{DT}}\right)$ dapat diselesaikan dengan metoda numerik aturan Simpson 1/3 segmen berganda yang dirumuskan pada persamaan (3) berikut : $I \cong(b-a) \frac{f\left(x_{o}\right)+4 \sum_{i=1,3,5}^{n-1} f\left(x_{i}\right)+2 \sum_{j=2,4,6}^{n-2} f\left(x_{j}\right)+f\left(x_{n}\right)}{3 n}$

dimana :

- $b=2 \pi$ dan $a=0, f\left(x_{0}\right)=C p(0) \cos (0)$ dan $f\left(x_{n}\right)=C p(2 \pi) \cos (2 \pi)$ untuk menyelesaikan persamaan (3.3).

$f\left(\mathrm{x}_{\mathrm{i}}\right)$ adalah perkalian dari fungsi data gasal dimana $i=1,3,5 \ldots n-1$.

- $f\left(\mathrm{x}_{\mathrm{j}}\right)$ adalah perkalian dari fungsi data genap dimana $\mathrm{j}=2,4,6 \ldots . . n-2$.

- $\mathrm{n}=$ jumlah data.

Kemudian data kualitatif berupa visualisasi aliran yaitu kontur velocity pathline dan velocity vector. Kedua hasil post processing kuantitatif dan kualitatif akan saling melengkapi untuk menjelaskan fenomena aliran pada silinder sirkular dengan penambahan square disturbance body.

\section{HASIL DAN PEMBAHASAN}

\subsection{Distribusi Koefisien Tekanan dan Visualisasi Aliran}

Untuk melihat perubahan yang terjadi di sepanjang kontur permukaan silinder mulai dari titik stagnasi, bubble separation, trasisi laminar ke turbulen sampai akhirnya terseparasi massif akan dianalisa 
melalui grafik koefisien tekanan yang ditunjukkan pada Gambar 4.

Pada Gambar 4 dilihat adanya perbedaan akselerasi maksimum yang terjadi pada setiap pergeseran sudut SDB (Square Disturbance Body). Semakin besar pergeseran sudut SDB, maka akan semakin meningkat adverse pressure gradient yang terjadi. Hal ini disebabkan karena free shear layer yang terseparasi dari body pengganggu (SDB) tidak lagi attach pada permukaan silinder, dikarenakan terbentuknya bubble separation pada permukaan body pengganggu. Hal ini mengakibatkan terjadi devisit momentum pada daerah ini sehingga tidak mampu lagi attach pada permukaan silinder utama akan tetapi langsung terseparasi massif, sehingga membentuk stream tube yang semakin lebar akibatnya terjadi peningkatan adverse pressure gradient (Gambar 5). Hal ini mengakibatkan separasi massif terjadi lebih awal. Fenomena ini terjadi pada konfigurasi silinder dengan SDB $\left(\alpha=50^{\circ}\right.$ dan $\left.60^{\circ}\right)$, dengan $\mathrm{Cp}_{\min }$ berturut-turut sekitar -4.2 dan -5.3 .

Sedangkan pada konfigurasi sudut SDB $\alpha=20^{\circ}$ dan $\alpha=30^{\circ}$ dan $\alpha=40^{\circ}$, separasi masif terjadi lebih lambat dibandingkan dengan silinder tunggal, dimana separasi pada silinder tunggal terjadi pada sudut kontur $\theta \approx 95^{\circ}$. Sedangkan konfigurasi sudut SDB $\alpha=20^{\circ}$ dan $\alpha=30^{\circ}$ dan $\alpha=40^{\circ}$ separasi masif baru terjadi berturut-turut pada sudut $\theta \approx$ $100^{\circ}, \theta \approx 103^{\circ}$ dan $\theta \approx 97^{\circ}$, seperti yang terlihat pada Gambar 4.

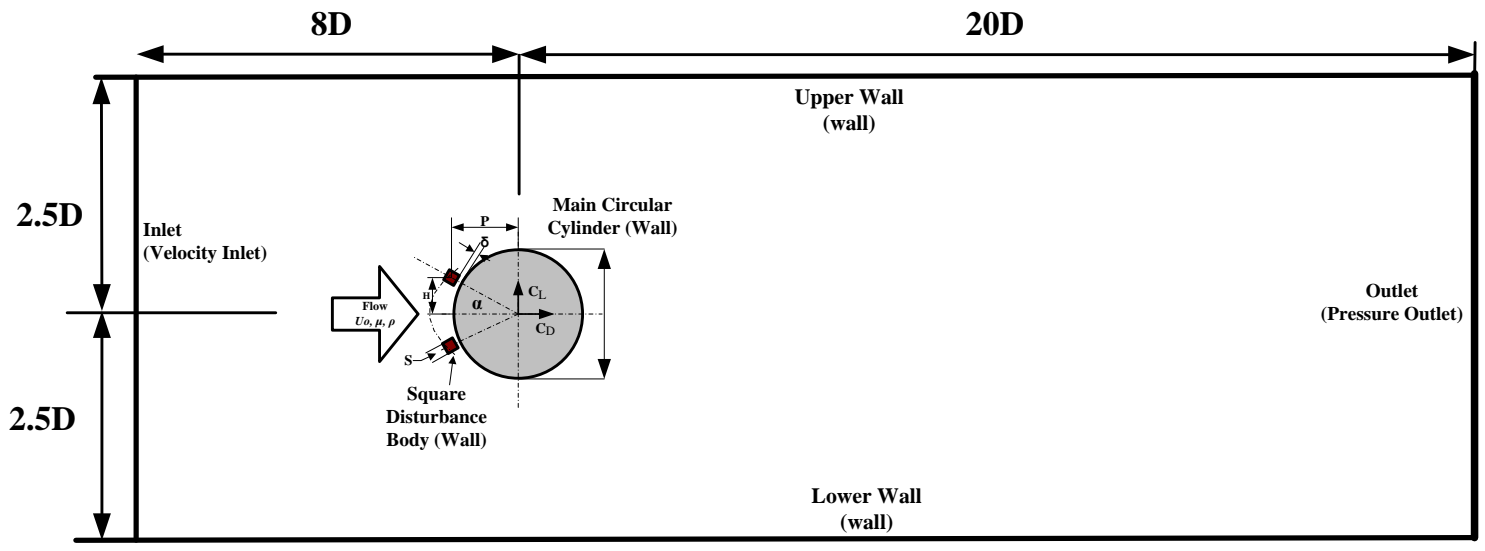

Gambar 2. Domain simulasi numerik

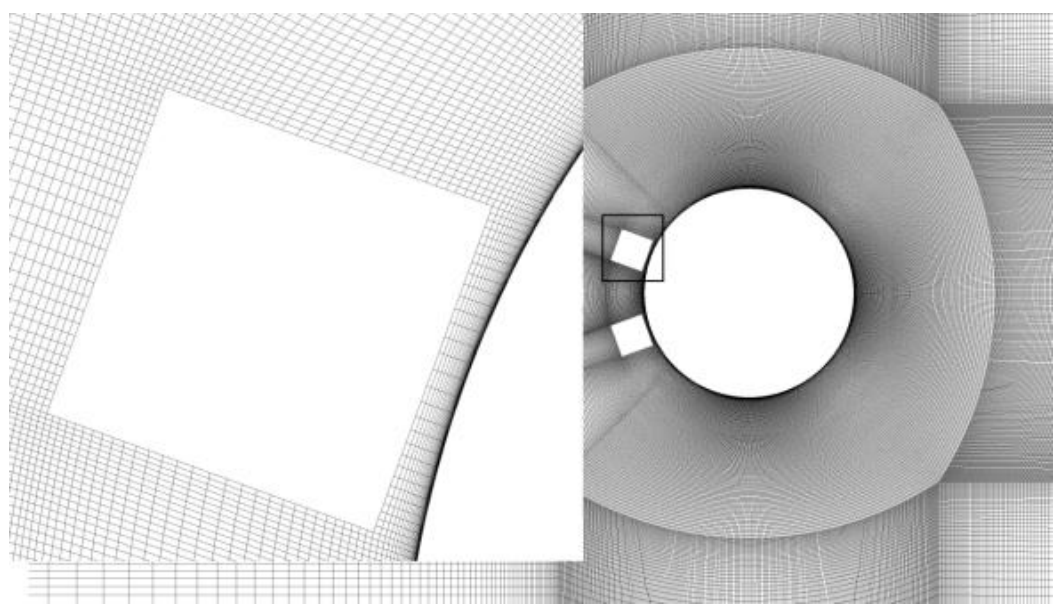

Gambar 3. Meshing qualidrateral map 
Peak yang terbentuk pada grafik koefisien tekanan (Gambar 4) pada SDB $\alpha=20^{\circ}, \alpha=30^{\circ}$ dan $\alpha=40^{\circ}$ ) mengindikasikan adanya bubble separation.. Momentum fluida yang terdefleksi dari bodi pengganggu (SDB) berinteraksi dengan momentum fluida pada free stream. Hal ini mengakibatkan terjadinya penambahan momentum sehingga aliran mampu attach pada kontur permukaan silinder sekitar sudut $\theta \approx 80^{\circ}, \theta \approx 85^{\circ}$ dan $\theta \approx 78^{\circ}$ (berturut-turut pada SDB $\alpha=20^{\circ}, \alpha$ $=30^{\circ}$ dan $\left.\alpha=40^{\circ}\right)$. Bertambahnya momentum pada daerah ini, mampu melawan adverse pressure gradient dan shear stress yang terjadi sehingga transisi aliran berubah lebih cepat ke turbulen. Akan tetapi pada sudut $\alpha=20^{\circ}$ dan $\alpha=40^{\circ}$ hanya sedikit mampu melawan shear stress dan adverse pressure gradient yang terjadi sehingga aliran langsung terseparasi massif.

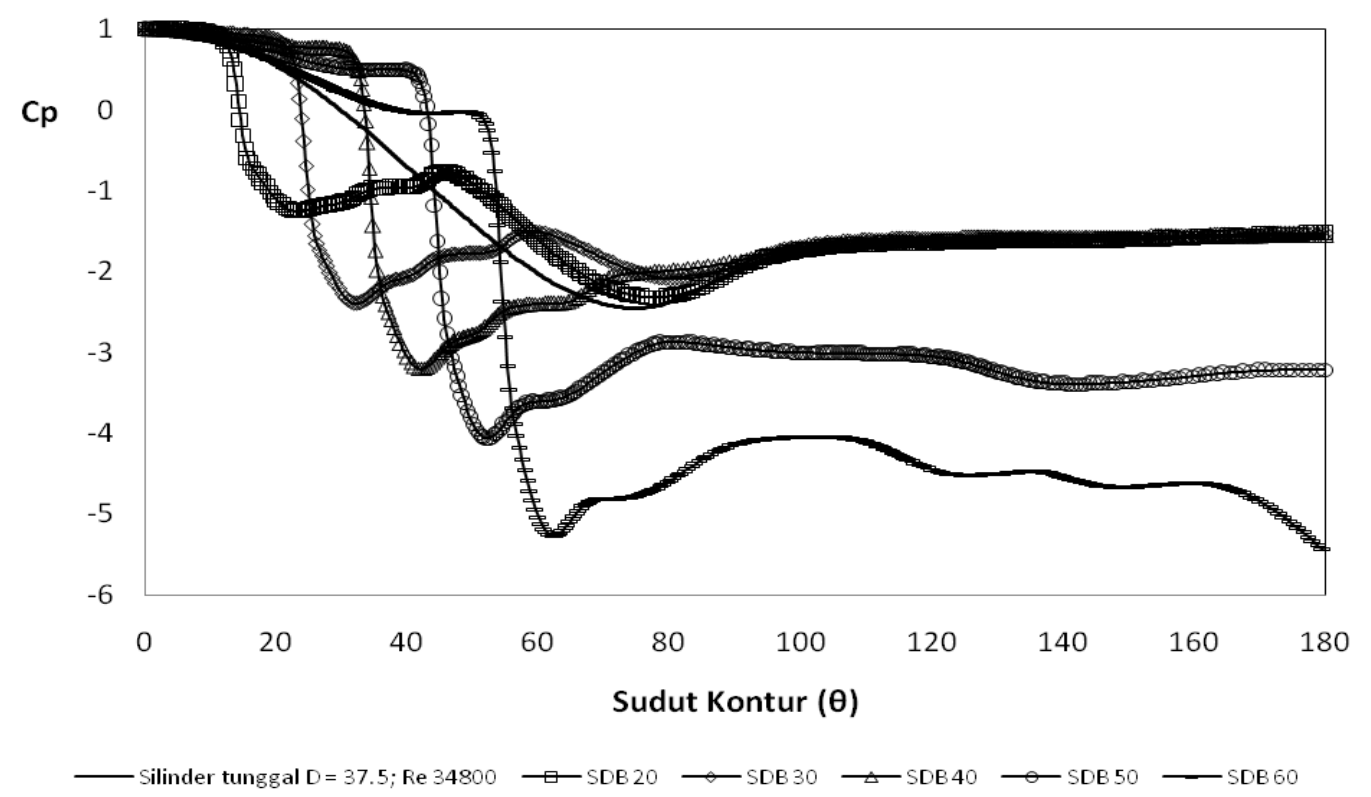

Gambar 4. Perbandingan distribusi koefisien tekanan (Cp) pada silinder dengan variasi sudut SDB

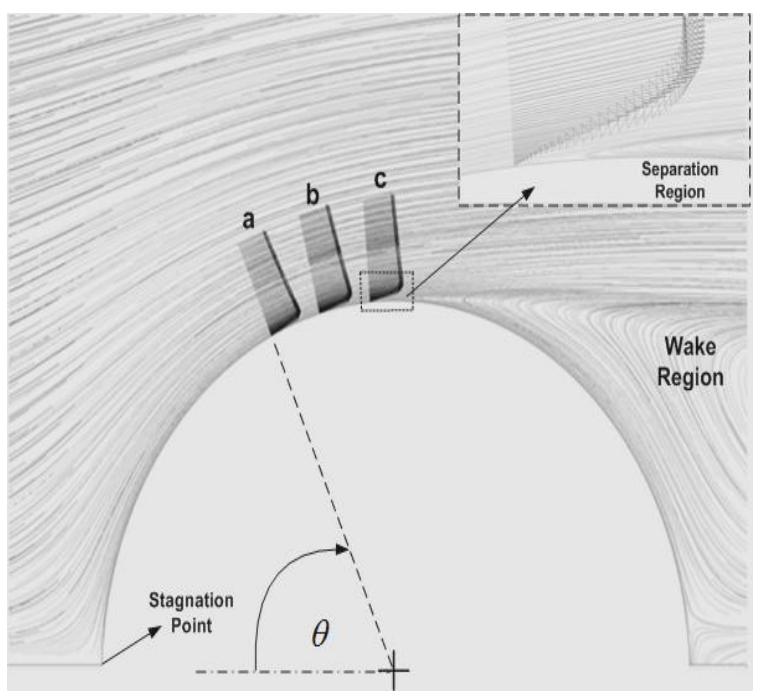

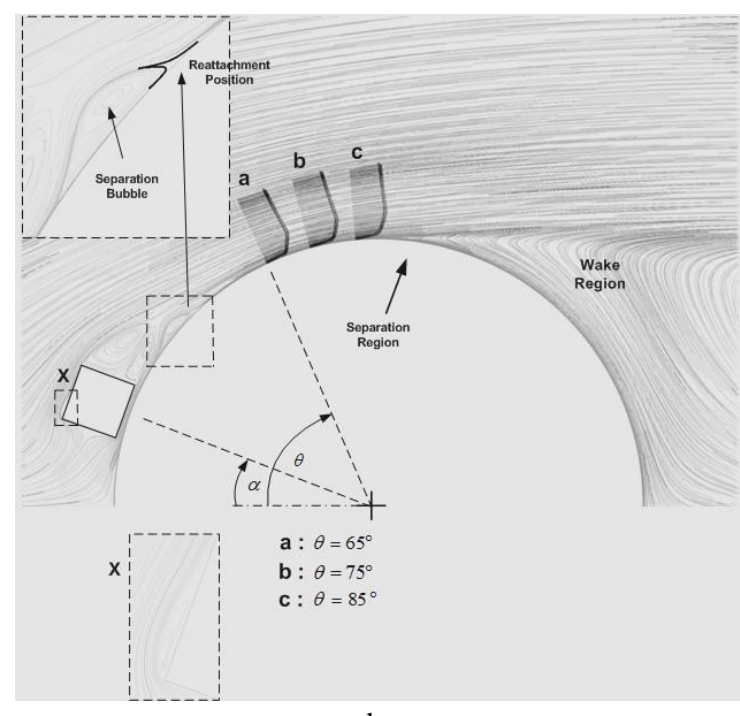

b 

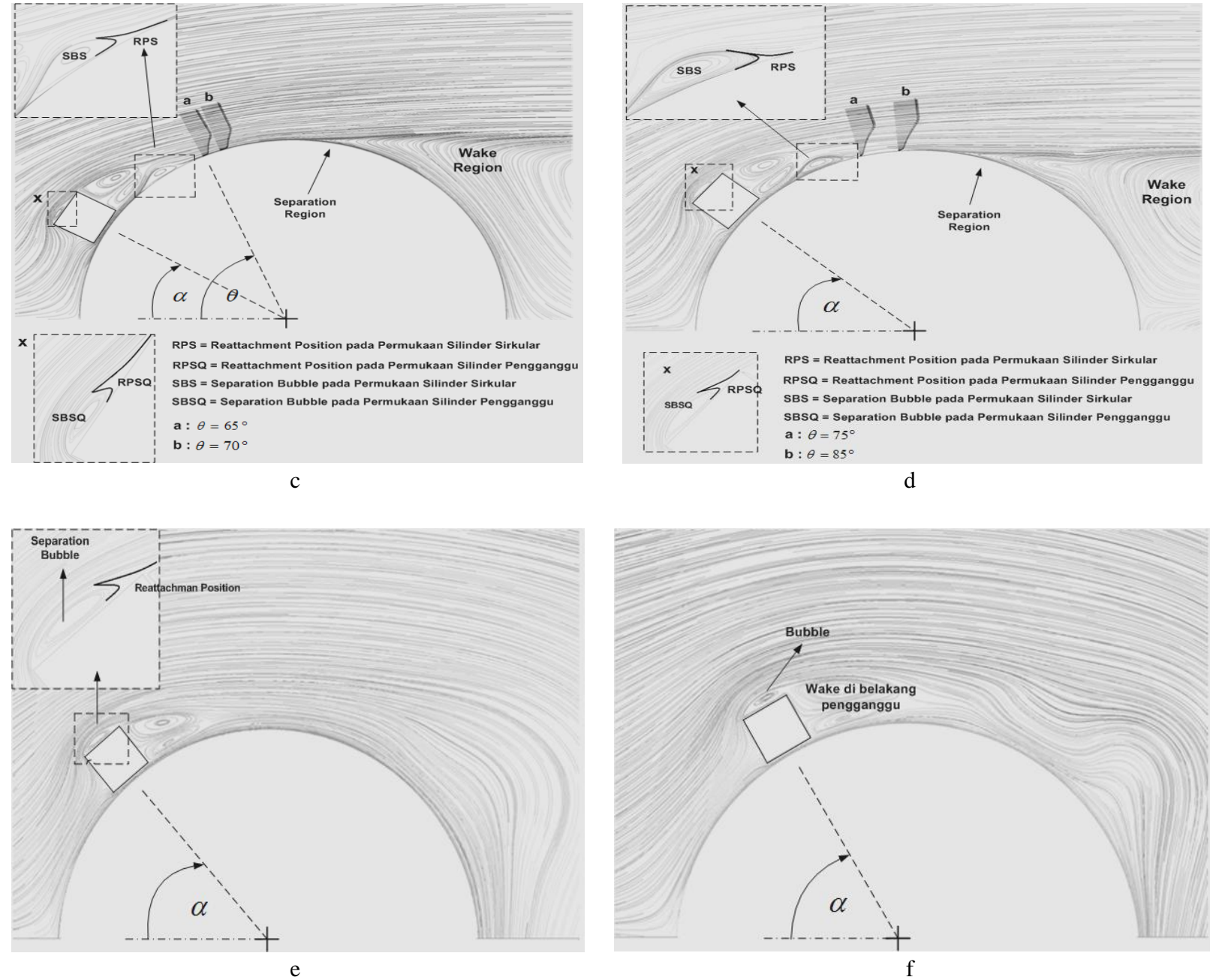

Gambar 5. Visualisasi aliran velocity pathline dan velocity vector. (a) Silinder tunggal ; (b) SDB $\alpha=20^{\circ}$; (c) $\operatorname{SDB} \alpha=30^{\circ}$; (d) $\operatorname{SDB} \alpha=40^{\circ}$; (e) $\operatorname{SDB} \alpha=50^{\circ}$; (f) $\operatorname{SDB} \alpha=60^{\circ}$

\subsection{Koefisien Drag Pressure (Cdp)}

Drag salah satunya disebabkan oleh tekanan aliran pada permukaan silinder. Drag akibat tekanan dapat diketahui melalui nilai koefisien drag pressure (Cdp). Grafik koefisien drag pressure (Cdp) dapat dilihat pada Gambar 6. Dari grafik dapat dilihat bahwa silinder dengan $\operatorname{SDB}\left(\alpha=30^{\circ}\right)$ paling optimum dalam usaha mereduksi gaya $\mathrm{drag}$ akibat tekanan dengan nilai Cdp $=0.58$.

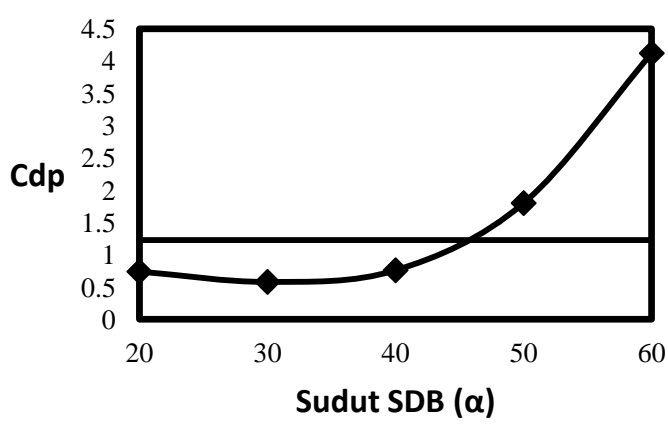

$\longrightarrow$ Silinder Tunggal $\longrightarrow$ Silinder dengan SDB

Gambar 6. Grafik koefisien drag pressure (Cdp) silinder tunggal dan silinder dengan SDB 


\section{KESIMPULAN}

Berdasarkan analisa yang telah diuraikan diatas, ada beberapa kesimpulan yang dapat dituliskan sebagai berikut:

1. Penggunaan Square Disturbance Body $(S D B)$ dapat mereduksi gaya drag, akan tetapi terbatas hanya penggunaan sudut SDB $\alpha=20^{\circ}, 30^{\circ}$ dan $40^{\circ}$, lebih dari itu sudah tidak memberikan kontribusi dalam pengurangan gaya $\mathrm{drag}$.

2. Pada silinder dengan SDB $\left(\alpha=20^{\circ}, 30^{\circ}\right.$ dan $40^{\circ}$ ) transisi aliran terjadi lebih cepat terjadi sehingga aliran lebih lambat terseparasi masif.

3. Silinder dengan SDB $\left(\alpha=30^{\circ}\right)$ merupakan sudut pengganggu yang paling optimum dalam usaha mereduksi gaya drag yaitu sebesar 53\%.

\section{DAFTAR PUSTAKA}

[1] T. Tsutsui, T. Igarashi,"Drag reduction of a circular cylinder in an air-stream", Jurnal of wind engineering and industrial aerodynamics Vol. 90, 527-541, 2002.

[2] S.S. Lee, S.I. Lee, C.W. Park, "Reducing the drag on a circular cylinder by upstream installation of a small control rod," Fluid dynamics research, Vol. 34, 233-250. 2004.

[3] P.F. Zhang, J.J. Wang, L.X. Huang, "Numerical simulation of flow around cylinder with an upstream rod in tandem at low Reynolds number", Applied Ocean Research 28, 183-192, 2006.

[4] A. Daloglu, "Pressure drop in a channel with cylinders in tandem arrangement", International Communication in Heat and Mass Transfer 35, 76-83, 2008.

[5] M.D. Alam, H. Sakamoto, M. Moriya, "Reduction of fluid forces acting on a single circular cylinder and two circular cylinders by using tripping rods", Journal of fluids and structures Vol. 18, 347-366, 2003.

[6] R.P. Putra, "Reduksi gaya hambat pada silinder sirkular dan reduksi pressure drop pada saluran sempit berpenampang bujur sangkar dengan menggunakan batang pengganggu berbentuk square cylinder", Tesis, Institut Teknologi Sepuluh, 2013

[7] P.D. Weidman, Wake transition and blockage effect on cylinder base pressure, Tesis, California Institute of Technologi, Pasadena, 1968.

[8] W.H. Bell, "Turbulence vs drag-some further consideration," Ocean Engineering. Vol. 10, No. 1, PP, 47-63,1983.

[9] M. Ozgoren, Flow structure in the downstream of square and circular cylinders, Celcuk University, Faculty of Engineering, Turkey, 2005. 